\title{
Deri lezyonlu enfektif endokardit olgusu
}

\author{
An infective endocarditis case with skin lesions
}

Kenan ÇADIRCI' ${ }^{1 a}$, Belma SEVIM¹', Derya DAL²

1Bölge Eğitim ve Araştırma Hastanesi, İç Hastalıkları Kliniği, Erzurum, ²Bölge Eğitim ve Araştırma Hastanesi, Göz Hastalıkları Kliniği, Erzurum - TÜRKIYE

\section{ÖZET}

Infektif endokardit, kalbin endotelyal yüzeylerinin mikrobiyal infeksiyonudur. Nadir fakat ciddi bir hastallktır ve yüksek mortalite ve mobidite riski taşır. İnfektif endokardit' in klinik belirti ve bulguları oldukça zengin ve değişkendir. Yüksek ateş, yeni başlayan veya özellik değiştiren kardiyak üfürüm, splenomegali, immün kompleks vaskülütine bağlı gelişen osler nodülleri, Janeway lezyonları ve göz dibi incelemesinde Roth spot görülebilir. Antibiyotik tedavisi hızıca başlanılmalı ve cerrahi tedavi gerekliliği açııından yakın takip edilmelidir. Bu yazıda deri bulguları ve yüksek ateş ile kliniğimize başvuran ve aort kapak vejetasyonu tespit edilerek infektif endokardit tanısı konulan ve başarılı aort kapak replasmanı ile kliniği tamamen düzelen bir bayan hasta sunulmuştur.

Anahtar Kelimeler: Infektif endokardit, aort kapak replasmanı, deri lezyonu

\section{ABSTRACT}

Infective endocarditis is the microbial infection of the endothelial surface of the heart. It is a rare but serious disease and carries a high risk of mortality and morbidity. The clinical findings and symptoms of infective endocarditis are various. High body temperature, sudden and variable cardiac murmur, splenomegaly, Osler nodules by immunocomplex vasculitis, Janeway lesions, Roth spots at funduscopy may be seen. Antibiotic therapy should be initiated quickly, and should be followed closely in terms of need for surgery. In this case report a female patient who had applied to our clinic with skin lesions, high body temperature and aortic valve vegetation diagnosed as infective endocarditis and later healed by successfull aortic valve replacement is presented.

Key Words: Infective endocarditis, aortic valve replacement, skin lesion 
Infektif endokardit (iE), çoğunlukla daha önceden bir kardiyak anomaliye sahip kişilerde, septal defekt veya korda tendinealar üzerinde, kalbin bir odacığını veya kapağını döşeyen endokardiyumun; bakteri, virüs, mantar, mikobakteri veya riketsiyal bir enfeksiyonun sonucu gelişen bir inflamatuar süreci olarak tanımlanmaktadır [1].

\section{Olgu Sunumu}

43 yaşında bayan hasta el ve ayak parmaklarında yeni oluşan kırmız।mor renkli deri lezyonları ve tırnaklarında kanama tarzında renk değişikliği şikayeti ile polikliniğimize başvurdu. Önceden tip 2 diabetes mellitus dışında bir hastalığı yokken, yaklaşık olarak bir ay önce diş çekimi yapılan ve son 15 günden beri şikayetleri başlayan hastanın, aynı zamandan beri nefes darlığı ve yüksek ateş şikayeti de olmuş. Yapılan fizik muayenesinde tansiyon arteriel:100/60 mmHg (brakial), nabız:108/dk (radial, ritmik), ateş: $38,2^{\circ} \mathrm{C}$ (aksiler) olarak bulundu. Diğer sistem muayenelerinde dalak $3 \mathrm{~cm}$ ve karaciğer $5 \mathrm{~cm}$ kadar palpabl, dinlemekle sol akciğer alt zonda solunum sesleri azalmış, dinlemekle kalp ritmik taşikardik, her odakta duyulabilen 3/6 sistolik üfürüm mevcut ve ayrıca ekstremite muayenesinde sağ el 5. parmak (Resim 1) ve sol el 4. parmak tırnak altında splinter hemoraji, yine sağ el 5. ve 1. parmakta (Resim 2) yumuşak dokuda ağrılı intradermal hemarajik lezyon, sol ayak baş parmak yumuşak dokuda ağrılı intradermal lezyon (Resim 3), sol ayak tabanına yakın alanda ağrısız eritemli alan (Resim 4) tespit edildi. Hastanın kliniğimize geliş tetkiklerinde glukoz: $274 \mathrm{mg} / \mathrm{dl}$, üre: $68 \mathrm{mg} / \mathrm{dl}$, kreatinin 1,7 mg/dl, AST:81 U/L (4-37), ALT: 66 U/L (0-42), Na:133 mmol/ L, K:3,5 mmol/L, lökosit: 20.100, hgb: $14,9 \mathrm{gr} / \mathrm{dl}$, plt:135.000, periferik yaymasında $\% 5$ parçall, $\% 11$ lenfosit, \%2 eozinofil, \%1 monosit ve \%1 atipik lenfosit, plt (++), eritrosit morfolojisi ise normokrom normositer olarak yorumlandı. Ayrıca bakılan CRP: 46,6 mg/dl (0-1) ve eritrosit sedimantasyon hızl: 79 mm/ saat olarak bulundu. Hastanın sorgulanmasında diabetes mellitus tanısı olduğu ve oral diabetik kullandığı ve bilinen başka sistemik hastalığı olmadığı, fakat yaklaşık olarak 1 yı önce Kardiyoloji kliniği tarafından yapılan ekokardiyografisinde fibrotik yapıda aort ve mitral kapak tespit edildiği ve kontrollere çağrıldığı öğrenildi. Hastanın bakılan tetkiklerinde trombositopenisi ve CRP yüksekliği olması, yapılan fizik muayenesinde üst ve alt ekstremitelerinde tespit edilen dermatolojik bulguların mevcudiyeti, splenomagali tespit edilmesi ve yaklaşık olarak son bir haftadan beri bir sağlık kuruluşu tarafından yüksek ateş şikayeti nedeni ile verilen oral antibiyotiğe rağmen yüksek seyreden ateş şikayeti de olması üzerine hastada infektif endokardit olabileceği düşünüldü. Bu sebeple hasta Enfeksiyon hastalıkları kliniğine danışıdı. Enfeksiyon hastalıkları kliniği; ard arda kan kültürleri gönderilerek, kendileri tarafından önerilen antibiyotik tedavisinin başlanımasını istedi. Kardiyoloji tarafından ekokardiyografisi yapılan hastada aort kapakta hareketli kitle, orta-ileri aort yetmezliği tespit edildi. Bunun üzerine hastaya transözafageal ekokardiyografi yapılarak aort kapak ventriküler ön yüzünde 1,7×0,8 cm boyutlu vejetasyon tespit edildi (Resim 5). Hastanın kliniğimize yatışında ve takiplerimizde alınan ard arda 3 kan kültüründe Metisiline duyarlı stafilokokkus aureus (MSSA) üretildi. Antibiyotik tedavisi olarak ceftriaxsone sodium $1 \mathrm{gr} 2 \times 1$ ve gentamycin sulfat $80 \mathrm{mg} 3 \times 1$ olarak uygulandı. Hastanın yapılan göz dibi incelemesinde Roth spot tespit edilemedi (Resim 6). Takiplerimizde an- tibiyotik tedavisine rağmen yüksek ateşleri gerilemedi ve yapılan kontrol ekokardiyografisinde vejetasyonu küçülmeyen hasta kalp damar cerrahisi kliniği ile görüşülerek, hastaya aynı klinik tarafından başarılı aort kapak replasmanı yapıldı.

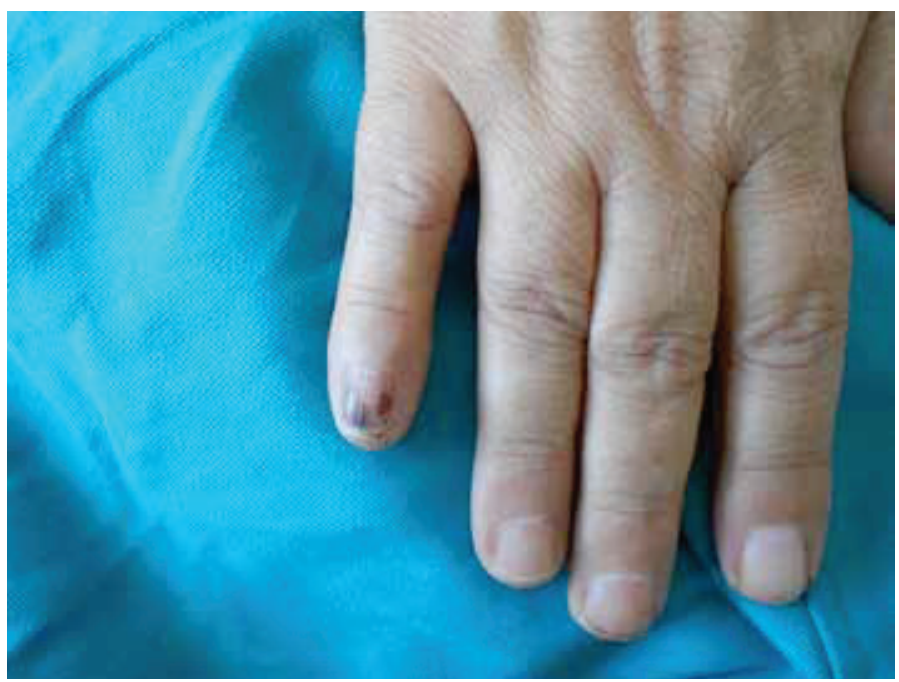

Resim1: Sağ el 5. parmakta Splinter hemoraji.

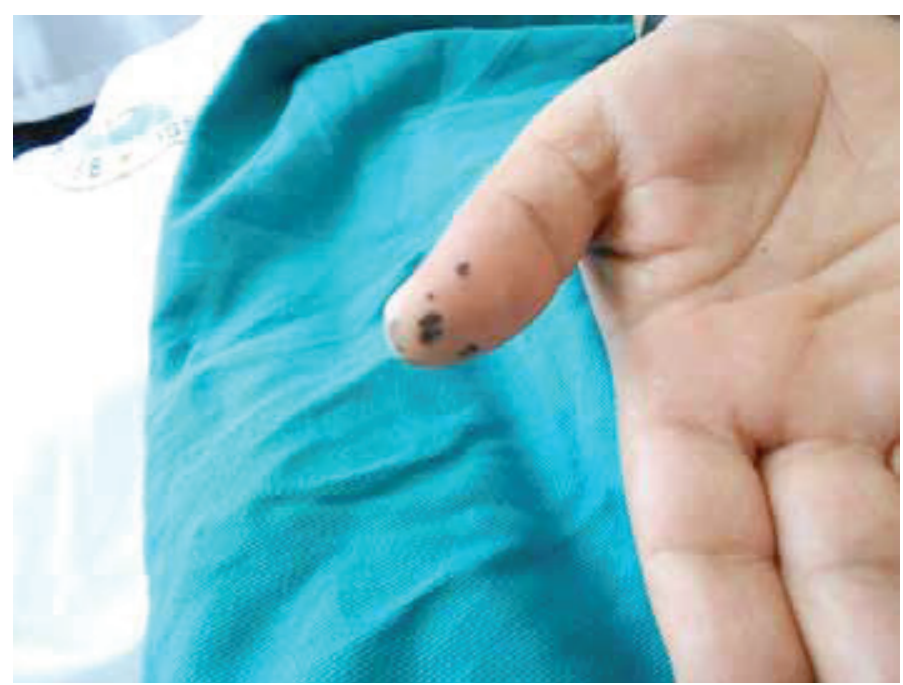

Resim 2: Sağ el 1. parmakta Osler nodülü.

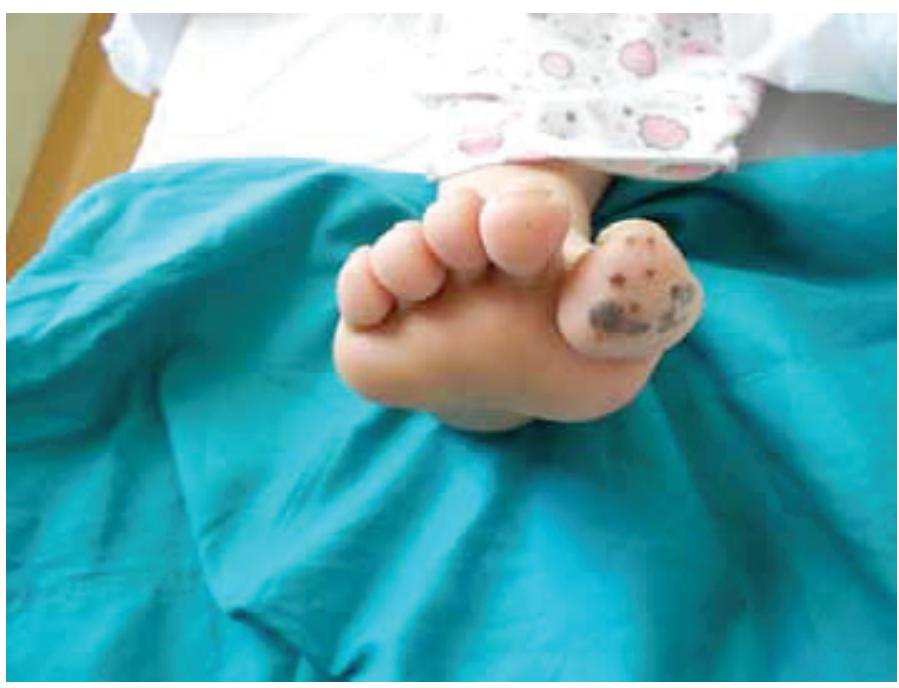

Resim 3: Sağ ayak 1. parmakta Osler nodülleri. 


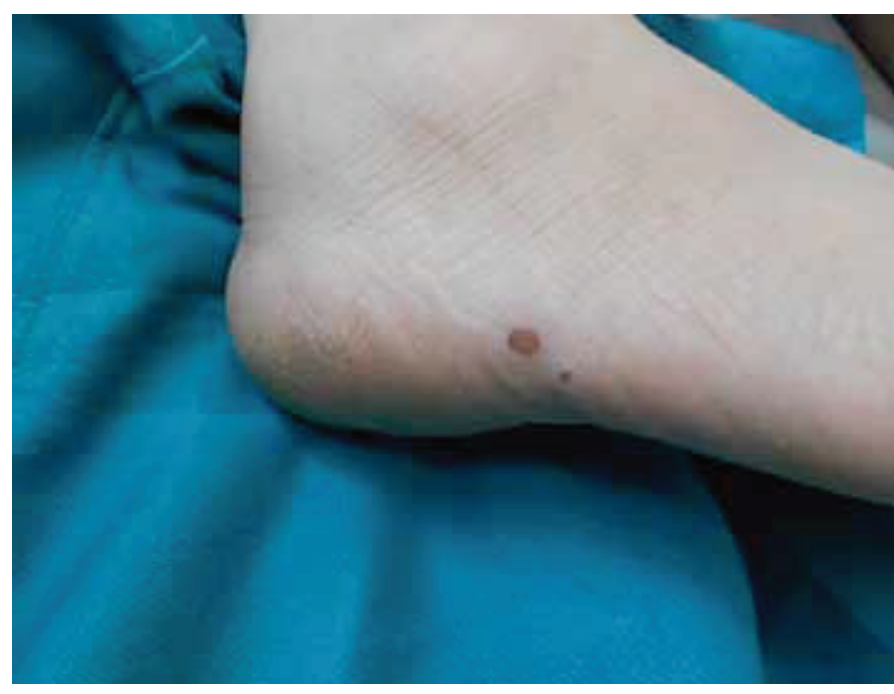

Resim 4: Sol ayak tabanına yakın alanda Janeway lezyonu.

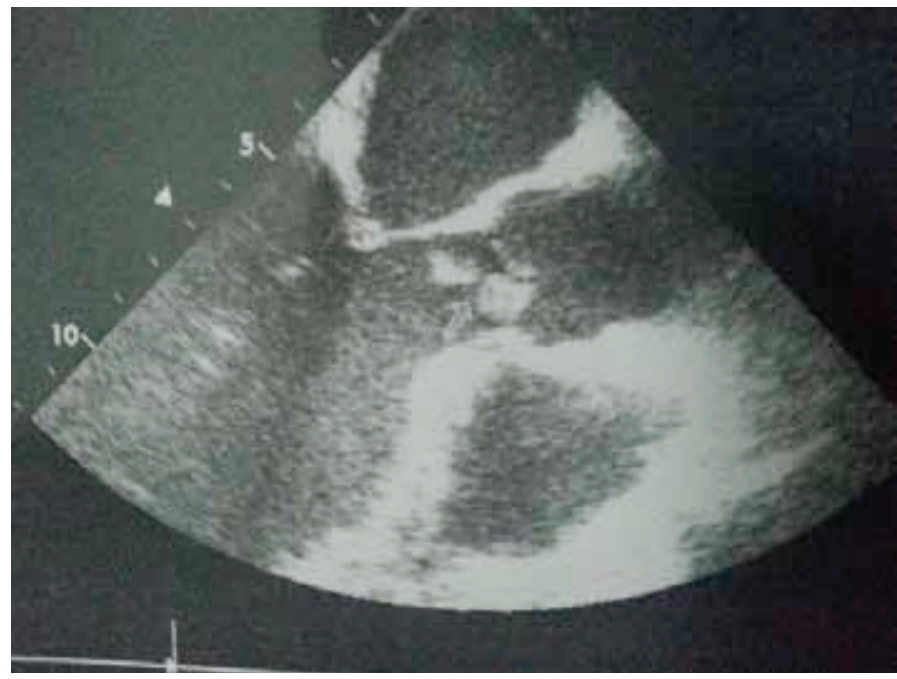

Resim 5: TEE' de aort kapak üzerinde 1,7×0,8 cm boyutlu vejetasyon.

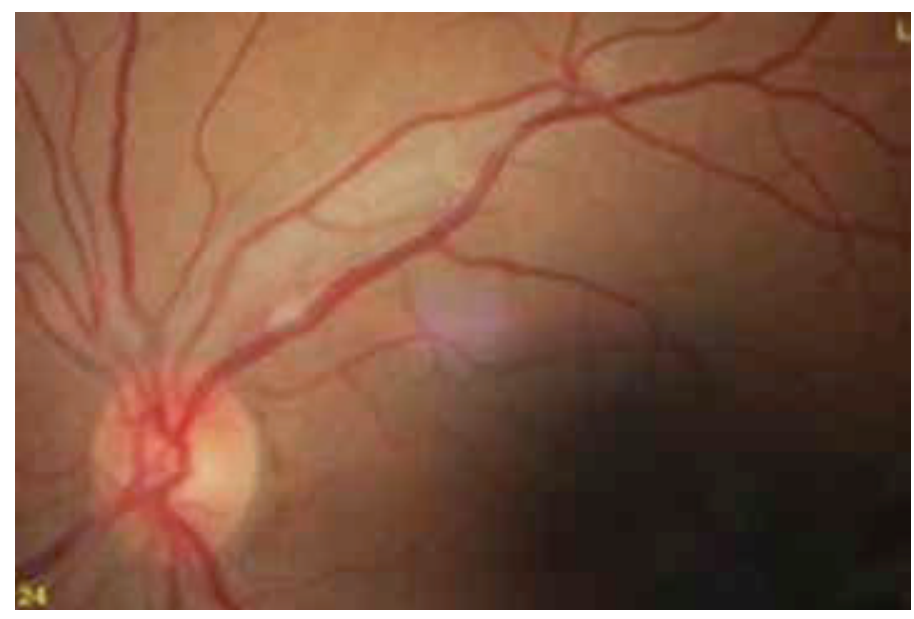

Resim 6: Normal göz dibi bulguları.

\section{Tartışma}

Infektif endokardit, çoğunlukla daha önceden bir kardiyak anomaliye sahip kişilerde, septal defekt veya korda tendinealar üzerinde, kalbin bir odacığının veya kapağını döşeyen endokardiyumun; bakteri, virüs, mantar, mikobakteri veya riketsiyal bir enfeksiyonun sonucu gelişen bir inflamatuar süreci olarak tanımlanmaktadır [1].
İnfektif endokardit uygun tanı ve tedaviye rağmen, yüksek morbidite ve \%9-30 gibi bir mortalite oranına sahip ciddi bir hastalıktır [2]. Tedavisi zor ve komplikasyonları potansiyel olarak yıkıcıdır. Ciddi bir hastalık olmasına rağmen neyise ki nadir görülen bir hastalıktır. Gelişmiş ülkelerde yıllık tahmini prevalansı 100.000 de 5 kişidir. Akut hastane mortalitesi \%15 civarındadır [3]. Hızlı tanı, etkili tedavi ve komplikasyonların çabuk tanınması hasta sonucunun iyi olması açısından kaçınılmazdır [4]. En sık başvuru şekli yavaş gidiş gösteren ateş, halsizlik, yorgunluk, atralji, miyalji, kilo kaybı ve terleme gibi nonspesifik bulgular olsa da kalp yetersizliği, üfürümde değişiklik, artrit, splenomegali ve immün yanıt-embolik fenomenlere bağlı nörolojik bulgular, peteşi, Osler nodülleri, Janeway lezyonları, Roth lekesi de görülebilir [5].

Hastaların üçte ikisinde yakın tarihte diş çektirme, dolgu yaptırma gibi dişle ilgili veya tonsilllektomi gibi cerrahi girişim öyküsü bulunmaktadır [6]. Bizim hastamızın da yaklaşık olarak 1 ay önce diş çekimi yaptırmış olduğu öğrenildi.

İnfektif endokardit tanısı için kullanılmakta olan Duke kriterleri 1994 yılında Durack ve ark. tarafından tanımlanmıştır [7]. Duke kriterlerinde, majör kriter olarak kan kültür pozitifliği ve ekokardiyografi bulguları ve minör kriter olarak da predispoze kalp hastalığı ve intravenöz ilaç kullanımı varlığı, yüksek ateş, vasküler fenomen varlığı (majör arteriel emboli, septik pulmoner infarkt vs.), immünolojik fenomen (glomeruonefrit, Osler nodulu, Janeway lezyonu) ve majör kritere uymayan pozitif kan kültürü varlığı gibi kriterler mevcutdur. Bizim hastamızın tanısında da Duke kriterleri kullanıldı. Hastamızın ard arda alınan 3 kan kültüründe de MSSA üremiş olması ayrıca yapılan transözafageal ekokardiyografisinde vejetasyon tespit edilmiş olması sebebiyle 2 majör kriteri ayrıca yüksek ateş, Osler nodülü, Jeneway lezyonu varlığı ve predispoze kalp hastalığının olması ile de minör kriterleri de karşılamaktaydı.

Stafilokokkus aureus, infektif endokardit vakalarının önde gelen nedenidir ve zamanla daha iyi tanı koyma ve tedavi etme imkanlarının gelişmiş olmasına rağmen mortalite yükssek kalmıştır. Fernadez Guerrero ve ark. [8] tarafından yapılan bir çalışmada stafilokok aureus'a bağı meydana gelen infektif endokardit vakalarının retrospektif incelendiği bir çalışmada sol taraf endokarditinde mitral kapak, aort kapağından daha sık bir tutulum göstermiştir (sırasıyla \%61 ve \%30). Bizim hastamız da ise aort kapak tutulumu gösterilmiştir.

Küçükateş ve ark. [9] tarafından ülkemizde yapılan, infektif endokardit tanısı konulan 22 hastayı içeren bir çalışmada, kan kültür pozitifliği \%50 vakada ( $n=11$ ) tespit edilmiş olup stafilokok $(n=4) \% 36,6$ ile en sık tespit edilen mikroorganizma olmuştur.

Yine Elbey ve ark. [10] tarafından; 13 merkezli ve 248 hastayı içeren bir çalışmada infektif endokarditli hastalardan en sık izole edilen bakterinin S. Aureus olduğu, konjestif kalp yetmezlğinin en yaygın görülen komplikasyon olduğu bildirilmiştir. Bizim hastamızında ard arda alınan üç kan kültüründe de MSSA (Meticillin sensitif Staf. Aureus) izole edildi.

MSSA'nın sorumlu olduğu toplumdan kazanılmış infektif endokardit vakalarında, mevcut etkenin penisiline dirençli ama metisiline duyarlı olması nedeni ile başlanacak tedavinin penisilinaza dirençli penisilin (oxasilin 
ve muadilleri) olması önerilmektedir [11]. Biz hastamızın tedavisinde oksasilin'in ülkemizde bulunmaması nedeni ile seftriaksone ve gentamisin tedavisi kullandık.

IE'in bazı klinik şekillerin ve komplikasyonlarının geliştiği vakalarda tek başına medikal tedavinin mortalitesi kabul edilemeyecek kadar yüksektir Bu vakalarda cerrahi girişim ile prognozun düzeltilmesi mümkündür. En sık cerrahi endikasyon oluşturan klinik tabloların başında IE seyri sırasında kapak disfonksiyonuna bağlı gelişen konjestif kalp yetmezliği gelmektedir. IE komplikasyonları arasında konjestif kalp yetmezliği gelişmesi, prognoz üzerine en önemli etkiye sahip olan komplikasyondur. Nativ kapak IE' de; aort kapak infeksiyonunda (\%29), mitral (\%20) veya triküspit kapak (\%8) infekisyonlarına göre daha sıkılıkla konjestif kalp yetmezliği gelişir [4].

Yine uygun antibiyotik tedavisine rağmen kliniğin ve ateşin düzelmemesi ve çok geniş izole vejetasyon ( >15 mm) olan vakalarda da cerrahi girişim önerilmektedir [11].

Bizim hastamızda da aort kapakta $17 \mathrm{~mm}$ çapında vejetasyon tespit edilmiş olması ve antibiyotik tedavisine rağmen vejetasyonun küçülmemiş olması ile beraber ateşlerini gerilememiş olması nedeni ile operasyon yapılması kararı alındı. Hastanın aort kapak replasmanı sonrası kliniğinde düzelme tespit edildi.

Sonuç olarak infektif endokardit, hızı tanı konulması gereken, tanı anından itibaren etkili ve güçlü antibiyotik tedavisi ile beraber cerrahi tedavi imkanlarının da sonuna kadar kullanımasını gerektiren bir klinik durum olarak karşımıza çıkmaktadır.

\section{Kaynaklar}

1. Pereira CA, Rocio SC, Ceolin MF, Lima AP, Borlot F, Pereira RS, et al Clinical and laboratory findings in a series of cases of infective endocarditis. J Pediatr (Rio J) 2003;79:423-8.

2. Colen TW, Gunn M, Cook E, Dubinsky T. Radiologic manifestations of extracardiac complications of infective endocarditis. Eur Radiol 2008;18: 243345.

3. O'Brien S, Dayer M, Benzimra J, Hardman S, Townsend M. Streptococcus pneumoniae endocarditis on replacement aortic valve with panopthalmitis and pseudoabscess. BMJ Case Reports 2011;doi:10.1136/ bcr.06.2011.4304.

4. Bayer AS, Bolger AF, Taubert KA, Wilson W, Steckelberg J, Karchmer AW, et al Diagnosis and management of infective endocarditis and its complications. Circulation 1998;98:2936-48.

5. Ergül Y, Yıldız EP, Nişli K, Aydoğan Ü, Dindar A, Aydınlı N at al. Rarely seen embolic events associated with infective endocarditis: case report. $J$ Child.2011;11:138-42.

6. Türkkan D, Yüksel F, Şamdancı E, Ak S. Septic embolsim of central nervous system due to infective endocarditis: An autopsy case. J Inonu University. 2010;17: 387-9.

7. Durack DT, Lukes AS, Bright DK. New criteria for diagnosis of infective endocarditis: utilization of spesific echocardiographic findings: Duke Endocarditis Service. Am J Med 1994;96: 200-9.
8. Fernandez Guerrero ML, Gonzalez Lopez JJ, Goyenechea A, Fraile J, de Gorgolas M. Endocarditis caused by Staphylococcus aureus: A reappraisal of the epidemiologic, clinical, and pathologic manifestations with analysis of factors determinig outcome. Medicine ( Baltimore).2009; 88:1-22. doi:10.1097/ MD.0b013e318194da65.

9. Küçükateş E, Gültekin N,Bağdatı Y. Cases of active infective endocarditis in a university hospital during a 10-year period. J Pak Med Assoc.2013; 63:1163-7.

10. Elbey MA, Akdağ S, Kalkan ME, Kaya MG,Sayın MR, Karapınar $H$ et al $A$ multicenter study on experience of 13 tertiary hospitals in Turkey in patients with infective endocarditis. The Anatolian Journal of Cardiology, 2013;13: 523-7.

11. ESC Kılavuzu. İnfektif endokardit tanı, korunma ve tedavisi kılavuzu. Avrupa Kardiyoloji Derneği. Horstkotte D, Follath F, Gutschik E, Lengyel M, Oto A, Pavie A, Soler-Soler J, Thiene G, von Graevenitz A. 2004. 30-40, 50-5. 